\title{
How Do Changes in Oral Health and Chewing Efficiency Affect the Changes of Oral-Health- Related Quality of Life of Nursing-Home Residents in the Short Term?
}

\author{
Andreas Zenthöfer' \\ Judith Ehret $\mathbb{D}^{\prime}$ \\ Melania Zajac' \\ Samuel Kilian (iD ${ }^{2}$ \\ Jana Kostunov (D) \\ Peter Rammelsberg' \\ Anna-Luisa Klotz (iD) \\ 'University of Heidelberg, Dental School, \\ Department of Prosthodontics, \\ Heidelberg, 69120, Germany; ${ }^{2}$ University \\ of Heidelberg, Institute of Medical \\ Biometry and Informatics, Heidelberg, \\ 69120 , Germany
}

Correspondence: Anna-Luisa Klotz University of Heidelberg, Dental School, Department of Prosthodontics, INF 400,

Heidelberg, 69120, Germany

Tel +49 622I 56-8799

Fax +49 6221 56-537

Email anna-luisa.klotz@med.uni-

heidelberg.de
Objective: To evaluate how changes in oral health and chewing efficiency affect the changes in oral-health-related quality of life (OHRQoL) of nursing-home residents over six months.

Methods: The study was conducted in nine nursing homes. Sociodemographic and general data were collected for all eligible individuals $(\mathrm{n}=150)$. Of these, 114 participants (mean age $82.0[ \pm 9.5]$ years, $77.2 \%$ women) were available for the following tests at baseline and six months later: a comprehensive examination of dental and general health, a two-colour mixing-ability test (to assess chewing efficiency), the Geriatric Oral Health Assessment Index (GOHAI; to evaluate the OHRQoL), and the Mini Mental State Examination (MMSE; to diagnose the presence and severity of dementia). Univariate and multivariate linear regression models were compiled to analyse possible factors affecting OHRQoL.

Results: For the final analysis, 108 participants were available. For the study cohort as a whole, a decrease in the number of functional occluding pairs $(\mathrm{C}: 0.195 ; p=0.034)$ and an increase in dental-treatment needs $(\mathrm{C}:-1.968 ; p=0.056)$ had the greatest negative effects on OHRQoL as expressed by the GOHAI score. For denture wearers, a deterioration of denture condition $(\mathrm{C}:-2.946 ; p=0.003)$ was the most important predictor for a decline in OHRQoL. Conclusion: A short-term decline in oral health and function affects the OHRQoL of nursing-home residents. The most important dental variables in this regard are the number of functional occluding pairs and dental and denture-related treatment needs.

Keywords: chewing-efficiency test, nursing home, OHRQoL, oral health

\section{Introduction}

The oral health of older people who live independently has improved in the last decade. However, the oral health of nursing-home residents has remained inadequate. ${ }^{1-3}$ Most nursing-home residents have dental or denture-related treatment needs and have missing teeth. ${ }^{4,5}$ These factors can affect chewing efficiency and have been linked to general health problems, such as an exacerbation of cardiovascular diseases and infectious diseases of the respiratory tract. ${ }^{6,7}$ However, health is not only defined as the absence of illness; it also consists of an individual's subjective perception of her or his health, ie health-related quality of life. ${ }^{8}$ In this context, oral-health-related quality of life (OHRQoL) appears to be important; several studies have confirmed that it substantially 
affects the subjective well-being and general quality of life of older people., ${ }^{9,10}$ Attempts have been made to isolate predictive factors for OHRQoL. However, the evidence available to nursing-home residents specifically is still limited. In this subgroup of older people, the level of care required by an individual has been observed to affect OHRQoL, ${ }^{11}$ as have dental variables (number of teeth, rehabilitation of missing teeth with dentures, denture condition). ${ }^{5,11-13}$ Several studies have speculated that these dental variables can affect OHRQoL by causing a reduction in chewing efficiency. ${ }^{5,14}$ However, none of these studies carried out a chewing-efficiency test, and limited information is available regarding the chewing efficiency of nursinghome residents specifically.

As far as the authors are aware, no study has longitudinally investigated how changes in oral health and function, including chewing efficiency, affect the OHRQoL of nursing-home residents. This information would, however, be useful for improving the OHRQoL of nursing-home residents. The aim of this study was, therefore, to evaluate the effects of changes in oral health and chewing efficiency on the changes of OHRQoL of nursing-home residents over a six-month period.

\section{Methods}

\section{Study Setting}

This study was approved by the local review board of the University of Heidelberg before its start (approval number S-420/2016). After approval, nine long-term care facilities in Baden-Württemberg and Hesse, two of the 16 federal states of Germany, were arbitrarily (rural and urban, respectively, nursing homes) selected for the study. A dentist provided written and oral information about the study to all residents and their legal representatives. All possible residents and legal representatives in case residents where not sui legis were asked to participate in this study and to give written and oral consent. Because the study protocol required a follow-up examination after six months, all residents who planned to move nursing home during the study period were excluded from participating. There were no other exclusion criteria, and 150 residents were included in the study. All assessments described below were conducted twice: at baseline (January 2018-July 2018) and six months later (July 2018 - January 2019).

\section{General Health and Cognitive Status}

The following information was obtained from participants' medical and care files: age (in years), gender $(1=$ women, 2 = men), height, weight, care level, number of chronic diseases and medications. This information was subsequently used to calculate body mass index. The participants' nutritional status was also assessed subjectively by dentists ( 1 = good (normal body stature); 2 = reduced (to thin or to thick); $3=$ bad (very thin or very thick). The level of care required by participants was categorised into five grades based on the German care insurance grading system. In this context mobility (10\%), cognitive function and communication (7.5\%), Behaviors and psychological problems $(7.5 \%)$, self-sufficiency $(40 \%)$, coping with and independent handling of illness or therapy-related demands and stresses (20\%), and design of everyday life and social contacts $(15 \%)$ were rated by trained appraisers. Residents with no need of care were classified as grade 0 . Residents with minor care needs and those with considerable care needs were classified as grades 1 and 2, respectively. Grade 3 included residents with high care needs, whereas grade 4 included those with very high care needs. Residents with very high care needs and additional specialized nursing requirements (eg severe dementia) were classified as grade 5 .

Cognitive status was evaluated by use of the Mini Mental State Examination (MMSE). ${ }^{15}$ The MMSE requires individuals to respond to 30 tasks and questions, whereby correctly performed tasks are awarded one point and failed ones are awarded none. Scores can therefore range from 0 to 30 points. As recommended in several previous studies, participants who attained a score below 24 points were classified as having dementia. ${ }^{15-18}$ All examinations were performed by two dentists who had been trained at the Memory Clinic of the University of Heidelberg before the start of the study.

\section{Dental Variables}

Each participant underwent a comprehensive dental examination that included an assessment of the following: dental status, the presence $(0=$ "does not have own teeth", 1 = "has own teeth") and number of teeth, the number of functional occluding pairs, the type and condition of the prosthesis worn and dental-treatment needs (eg caries; $0=$ "no treatment needed", 1 = "treatment needed"). The number of functional occluding pairs was defined as the number of teeth with static contacts (anterior and 
posterior teeth) between the maxillary and mandibular dentitions. The condition of the prosthesis worn, if applicable, was evaluated using the category "dentures" of the Oral Health Assessment Tool (OHAT). ${ }^{19}$ The OHAT is a reliable and valid assessment instrument for oral health and can also be used by non-dental health professionals. The rating was dichotomous: $0=$ adequate denture (no broken areas or teeth, dentures worn regularly); $1=$ in need of repair (at least one broken area/tooth or dentures loose). ${ }^{19}$ For analytical purposes, the types of prosthesis were sorted into four categories: 1) natural teeth or fixed dental prosthesis (FDP); 2) removable dental prosthesis (RDP); 3) complete denture (CD); and 4) edentulous with no prosthesis (ENP). For the variable "total denture status", each participant was classified according to the weaker restored jaw. If treatment needs were diagnosed, participants or/and the legal representatives were informed about it and dental treatment was suggested.

All dental examinations were performed by two dentists trained in the examination of older patients at the Department of Prosthodontics, University of Heidelberg, before the start of the study.

\section{Chewing Efficiency}

Chewing efficiency was evaluated by means of the twocolour mixing-ability test, which was described by Schimmel et al in 2007. Commercially available chewing gum (Hubba Bubba Tape Gum ${ }^{\mathrm{TM}}$; The Wrigley Company Ltd, Plymouth, Devon, UK) in the colours blue (flavour: Sour Berry) and pink (flavour: Fancy Fruit) served as test food. The two types of chewing gum were prepared for the study by cutting strips $30 \mathrm{~mm}$ in length from each colour and sticking them together. The final dimensions of the strips were $30 \times 18 \times 3 \mathrm{~mm} .^{20}$ The dentists instructed all participants in the same way, asking them to chew the test food for 20 chewing cycles. Afterwards, the gum samples were spat into a transparent plastic bag before a visual evaluation of mixing ability was performed by the dentists. The five categories were: 1 = chewing gum not mixed, impressions of cusps or folded once; 2 = large parts of chewing gum unmixed; 3 = bolus slightly mixed, but bits of unmixed original colour remain; $4=$ bolus well mixed, but colour not uniform; $5=$ bolus perfectly mixed with uniform colour. The chewing-gum samples were then flattened into wafers $1 \mathrm{~mm}$ thick and were scanned from both sides at a resolution of 1200 dots per inch using a flatbed scanner. The scanned chewing-gum samples were stored as.jpg files. The pictures were then imported into
ViewGum software (dHAL Software, version 1.4.1.0; Kifissia, Greece) and analysed according to the protocol of Halazonetis et al. ${ }^{21}$ Inadequate mixing was presented linearly and had a greater variance of hue than complete mixing.

\section{OHRQoL Assessment}

The German version of the Geriatric Oral Health Assessment Index (GOHAI) was used to assess OHRQoL. $^{22}$ The GOHAI requires individuals to answer 12 questions related to pain and/or discomfort and physical and/or psychosocial function regarding their oral condition. In this study, the simple count score for GOHAI (SCGOHAI) was used to identify extreme results for the GOHAI on a three-point scoring scale ( 2 = always, $1=$ sometimes and $0=$ never). Questions 3, 5, and 7 are inversely scaled ( $0=$ always, $1=$ sometimes, $2=$ never $)$. The final GOHAI score can therefore range from 0 to 24 points. Patients with a low GOHAI score have poor OHRQoL. ${ }^{22,23}$ This simple version of the GOHAI was used because many participants in the study sample had at least mild cognitive impairment. ${ }^{24}$

In this study, the dentists read the questions slowly to the participants. A copy of the questionnaire was also handed to participants to enable them to read the questions themselves. If the participant gave invalid answers, or if the dentist believed that the participant was unable to differentiate between the answer categories, the question was repeated. Such events were documented, and the results from these participants were excluded from statistical analysis (discussed below).

\section{Statistical Analysis}

Mean values, standard deviations, counts and frequencies were used to descriptively present the results of the baseline and follow-up examinations. Results were given as means ( \pm SD) or counts (frequency \%). In addition, a drop-out analysis was conducted at the level of baseline characteristics. In this context, baseline characteristics of the drop-outs were presented as means ( \pm SD) or numbers (frequency \%). Furthermore, scaled variables were compared using the Mann Whitney $U$-Test and categorical variables were compared using chi-square test.

A univariate linear regression model was used to assess the longitudinal association between changes in participants' OHRQoL (GOHAI) and changes in the independent variables. In this context, a change in continuous variables (number of teeth, number of occluding pairs, BMI, 
objective evaluation of the chewing function) was defined as the difference between the follow-up and baseline assessments. A change in ordinally scaled variables (care level, total denture status, nutritional status, subjective evaluation of the chewing function) was defined dichotomously as a deterioration of the score $(0=$ equal/better; 1 = worse).

Multivariate linear regression was also conducted, after a stepwise selection of variables using the $p$-value, to capture the independent variables most strongly associated with a change in the dependent variable (GOHAI). First, the stepwise variable selection algorithm excluded all variables with a $p$-value greater than 0.5 in the univariate linear regressions and, second, performed a backward step in which the variable with the highest $p$-value was excluded. Third, for every variable not included, the algorithm checked whether the $p$-value, if re-included in the model, was below the threshold of 0.05 . If so, the excluded variable with the smallest $p$-value was re-included (forward step). The backward and forward steps were reiterated until all included variables were significant or only one variable was left. Variables with a $p$-value of $\leq$ 0.05 were included in the final model.

Univariate and multivariate linear regression analyses were conducted for all participants and for denture wearers (RPD, CD, ENP) only.

Statistical analysis was performed by use of the software R, version 3.4.2 (R Core Team; Auckland, New Zealand). $P$-values of less than 0.05 were regarded as significant.

\section{Results}

\section{Characterisation of the Study Population}

Out of 150 older people initially included, 114 (76\%) had a comprehensive dental and general-health examination and 108 had a GOHAI examination (72\%) at both measurement points (i.e. at baseline and six months later).

Among the analysed sample, the mean age at baseline was $82.0( \pm 9.5)$ years, and $77.2 \%$ of participants were women. The mean number of chronic diseases at baseline was $5.9( \pm 3.5)$, and the mean number of medications taken was $8.7( \pm 3.7)$. The mean MMSE score at baseline was $18.9( \pm 8.4)$ points, and most participants suffered from at least very mild dementia. The mean GOHAI score of the sample at baseline was 20.5 ( \pm 3.5$)$. After six months, the mean GOHAI of the sample was 20.2 $( \pm 3.7)$.
The mean number of remaining teeth at baseline was 9.2 ( \pm 9.6$)$, and participants had a mean number of 7.7 $( \pm 4.7)$ functional occluding pairs. After six months, the mean number of teeth $(8.9[ \pm 9.3])$ and functional occluding pairs $(4.9[ \pm 3.6])$ had decreased. Thirty-one $(27.2 \%)$ participants had natural teeth or wore an FDP at baseline, $19(16.7 \%)$ wore an RDP, $50(43.9 \%)$ wore a CD and 14 (12.3\%) were ENP in at least one jaw. At baseline, 78.1\% of the participants had dental-treatment needs, and the denture condition of most denture wearers was inadequate $(66.7 \%)$. After six months, the situation had deteriorated; $85.1 \%$ of participants had treatment needs and the denture condition of $76.7 \%$ of denture wearers was inadequate. Due to general health problems, three participants were unable to pass the chewing efficiency test. Out of the analysed sample, chewing efficiency at baseline, as determined by the variance of hue, was 0.56 ( \pm 0.25$)$. Comparing the included participants and the drop-outs only a weak difference was found between the number of teeth $(p=0.043)$. For detailed results see Table 1 .

\section{Univariate Association with OHRQoL}

For all participants who took the GOHAI twice $(\mathrm{n}=108)$, a decrease in the number of functional occluding pairs was significantly associated with a decrease in GOHAI score and therefore a worse OHRQoL (C: 0.195; $p=0.034)$. Furthermore, the univariate regression model detected a trend whereby an increase in treatment needs led to a decrease in GOHAI score and thus a worse OHRQoL $(\mathrm{C}:-1.968 ; p=0.056)$. In this context, the GOHAI score of participants with increasing treatment needs decreased by 1.968 points more on average than the score of participants with no increasing treatment needs. None of the other variables had an effect on the change in the OHRQoL of participants (Table 2).

For denture wearers $(n=82)$, a decrease in the number of functional occluding pairs (C: $0.234 ; p=0.019)$ and an increase in treatment needs $(\mathrm{C}:-2.611 ; p=0.031)$ were both significantly associated with a decrease in GOHAI score (and thus a decline in OHRQoL). Furthermore, for denture wearers, the condition of the denture proved relevant. In this context, the GOHAI score of participants whose denture condition had deteriorated decreased by 2.946 points more on average than the score of the other participants (C: $-2.946 ; p=0.003)$. None of the other variables significantly affected the change in the GOHAI score $(p>0.05)$. Detailed results of these analyses are presented in Table 3. 
Table I Participant Characteristics at Baseline and After Six Months $(n=114)$ and Drop-Outs $(n=36)$

\begin{tabular}{|c|c|c|c|c|}
\hline & $\begin{array}{c}\text { Drop- } \\
\text { Outs }\end{array}$ & $\begin{array}{r}\text { Participant } \\
\text { Characteristics } \\
\text { at Baseline }\end{array}$ & $\begin{array}{r}\text { Comparison Between Drop-Outs } \\
\text { and Included Participants at } \\
\text { Baseline ( } p \text {-value) }\end{array}$ & $\begin{array}{r}\text { Participant } \\
\text { Characteristics at } \\
\text { Six-Month Follow-Up }\end{array}$ \\
\hline Age & $82.4(10.8)$ & $82.0(9.5)$ & 0.559 & $82.5(9.5)$ \\
\hline \multicolumn{5}{|l|}{ Gender } \\
\hline Women & $25(69.4 \%)$ & $88(77.2 \%)$ & 0.472 & $88(77.2 \%)$ \\
\hline Men & II (30.6\%) & $26(22.8 \%)$ & & $26(22.8 \%)$ \\
\hline MMSE & $20.0(8.6)$ & $18.9(8.4)$ & 0.338 & $17.3(9.0)$ \\
\hline \multicolumn{5}{|l|}{ Care level } \\
\hline 0 & I (2.8\%) & $3(2.6 \%)$ & 0.491 & $2(1.8 \%)$ \\
\hline I & $2(5.6 \%)$ & $4(3.5 \%)$ & & $3(2.6 \%)$ \\
\hline 2 & $7(9.4 \%)$ & 38 (33.3\%) & & 36 (3I.6\%) \\
\hline 3 & II (30.6\%) & $35(30.7 \%)$ & & 37 (32.5\%) \\
\hline 4 & 14 (38.9\%) & $28(24.06 \%)$ & & 27 (23.7\%) \\
\hline 5 & I (2.8\%) & $6(5.3 \%)$ & & $9(7.9 \%)$ \\
\hline Body mass index & $26.6(5.4)$ & $28.0(7.0)$ & 0.376 & $27.8(6.8 \%)$ \\
\hline \multicolumn{5}{|l|}{ Nutritional status } \\
\hline Good & 27 (75.0\%) & $93(81.6 \%)$ & 0.053 & $80(70.2 \%)$ \\
\hline Reduced & $6(16.7 \%)$ & 20 (I7.5\%) & & $26(22.8 \%)$ \\
\hline Bad & $3(8.3 \%)$ & I (0.9\%) & & $8(7 \%)$ \\
\hline Number of teeth & $12.8(9.9)$ & $9.2(9.6)$ & 0.043 & $8.9(9.3)$ \\
\hline \multicolumn{5}{|l|}{ Natural teeth } \\
\hline Yes & $30(83.3 \%)$ & 77 (67.5\%) & 0.106 & 77 (67.5\%) \\
\hline No & $6(16.7 \%)$ & 37 (32.5\%) & & 37 (32.5\%) \\
\hline \multicolumn{5}{|l|}{ Treatment needs } \\
\hline Yes & 31 (86.1\%) & 89 (78.1\%) & 0.416 & 97 (85.1\%) \\
\hline No & $5(13.9 \%)$ & 25 (2I.9\%) & & 17 (I4.9\%) \\
\hline Pressure & $(n=23)$ & & & \\
\hline Yes & I8 (78.3\%) & 0 (79.5\%) & 1 & $92(80.7 \%)$ \\
\hline No & $5(21.7 \%)$ & $18(20.5 \%)$ & & 22 (19.3\%) \\
\hline \multicolumn{5}{|l|}{ Total denture status } \\
\hline FDP/ natural teeth & $14(38.9 \%)$ & 31 (27.2\%) & 0.236 & $31(27.2 \%)$ \\
\hline RDP & $8(22.2 \%)$ & $19(16.7 \%)$ & & $17(14.9 \%)$ \\
\hline$C D$ & $9(25.0 \%)$ & $50(43.9 \%)$ & & $44(38.6 \%)$ \\
\hline ENP & $5(13.9 \%)$ & $14(12.3 \%)$ & & $22(19.3 \%)$ \\
\hline Number of functional occluding pairs & $7.7(4.8)$ & $7.7(4.7)$ & 0.998 & $4.9(3.6)$ \\
\hline \multicolumn{5}{|l|}{ Denture condition $(n=87 / 86)$} \\
\hline Adequate & $8(22.2 \%)$ & $9(33.3 \%)$ & 1 & $20(23.3 \%)$ \\
\hline Inadequate & $15(4 I .7 \%)$ & $58(66.7 \%)$ & & $66(76.7 \%)$ \\
\hline Chewing efficiency $(n=1|| / \mid 106)$ & $0.5(0.3)$ & $0.6(0.3)$ & 0.557 & $0.5(0.3)$ \\
\hline
\end{tabular}


Table I (Continued).

\begin{tabular}{|c|c|c|c|c|}
\hline & $\begin{array}{c}\text { Drop- } \\
\text { Outs }\end{array}$ & $\begin{array}{r}\text { Participant } \\
\text { Characteristics } \\
\text { at Baseline }\end{array}$ & $\begin{array}{r}\text { Comparison Between Drop-Outs } \\
\text { and Included Participants at } \\
\text { Baseline ( } p \text {-value) }\end{array}$ & $\begin{array}{r}\text { Participant } \\
\text { Characteristics at } \\
\text { Six-Month Follow-Up }\end{array}$ \\
\hline \multicolumn{5}{|c|}{$\begin{array}{l}\text { Subjective evaluation of chewing } \\
\text { efficiency }(n=111 / 106)\end{array}$} \\
\hline I & $12(34.3 \%)$ & 45 (40.5\%) & 0.409 & 49 (46.2\%) \\
\hline 2 & 4 (II.4\%) & 25 (22.5\%) & & $16(15.1 \%)$ \\
\hline 3 & $8(22.9 \%)$ & $19(17.1 \%)$ & & 20 (18.9\%) \\
\hline 4 & $10(28.6 \%)$ & 20 (18.0\%) & & $17(16.0 \%)$ \\
\hline 5 & I (2.9\%) & $2(1.8 \%)$ & & $4(8 \%)$ \\
\hline GOHAI $(n=108)$ & $21.3(3.1)$ & $20.5(3.5)$ & 0.148 & $20.2(3.7)$ \\
\hline
\end{tabular}

Notes: The five categories for subjective evaluation of chewing efficiency are: 1 = chewing gum not mixed, impressions of cusps or folded once; 2 = large parts of chewing gum unmixed; $3=$ bolus slightly mixed, but bits of unmixed original colour remain; $4=$ bolus well mixed, but colour not uniform; $5=$ bolus perfectly mixed with uniform colour. Chewing efficiency: inadequate mixing has a greater variance of hue than complete mixing. Significant $p$-values are marked in bold. Data are presented as means (SD) or counts (frequency).

Abbreviations: MMSE, Mini Mental State Examination; FDP, fixed dental prosthesis; RDP, removable dental prosthesis; CD, complete denture; ENP, edentulous with no prosthesis; GOHAI, Geriatric Oral Health Assessment Index (min: 0, max=24); n, number of participants.

Table 2 Univariate Regression Analysis with GOHAI Difference as the Dependent Variable and Changes in Dental Target Variables Over the Study Period as Independent Variables

\begin{tabular}{|c|c|c|c|c|}
\hline Variable & C & $\begin{array}{l}95 \% \mathrm{CI} \\
\text { LB }\end{array}$ & $\begin{array}{l}95 \% \mathrm{CI} \\
\text { UB }\end{array}$ & p-value \\
\hline \multicolumn{5}{|c|}{ Change in GOHAI $(n=108)$} \\
\hline Age & -0.014 & -0.085 & 0.058 & 0.709 \\
\hline Gender & -0.119 & $-|.70|$ & 1.463 & 0.882 \\
\hline Change in body mass index & 0.015 & -0.322 & 0.352 & 0.930 \\
\hline Change in MMSE score & -0.076 & -0.266 & 0.114 & 0.430 \\
\hline Change in number of teeth & 0.387 & -0.313 & 1.088 & 0.276 \\
\hline $\begin{array}{l}\text { Change in number of } \\
\text { occluding pairs }\end{array}$ & 0.195 & 0.015 & 0.376 & 0.034 \\
\hline $\begin{array}{l}\text { Change in presence of own } \\
\text { teeth }\end{array}$ & 2.821 & -2.100 & 7.741 & 0.258 \\
\hline $\begin{array}{l}\text { Change in total denture } \\
\text { status }\end{array}$ & -0.313 & -2.272 & 2.101 & 0.798 \\
\hline $\begin{array}{l}\text { Change in level of care } \\
\text { needed }\end{array}$ & 0.302 & $-|.82|$ & 2.425 & 0.778 \\
\hline $\begin{array}{l}\text { Change in total treatment } \\
\text { needs }\end{array}$ & -1.968 & -3.984 & 0.047 & 0.056 \\
\hline Change in nutritional status & -0.144 & -1.935 & 1.646 & 0.873 \\
\hline Change in malnutrition & 1.280 & -5.683 & 8.244 & 0.716 \\
\hline $\begin{array}{l}\text { Change in chewing function, } \\
\text { objective }(n=101)\end{array}$ & -1.024 & -4.062 & 2.015 & 0.505 \\
\hline $\begin{array}{l}\text { Change in chewing function, } \\
\text { subjective }(n=10 I)\end{array}$ & 0.193 & -1.356 & 1.742 & 0.805 \\
\hline
\end{tabular}

Note: Significant $p$-values are marked in bold.

Abbreviations: $C$, regression coefficient; LB, lower boundary; UB, upper boundary; GOHAl, Geriatric Oral Health Assessment Index; MMSE, Mini Mental State Examination; n, number of participants.

\section{Multivariate Association with OHRQoL}

After selecting variables in the multivariate regression model for all participants, a decrease in the number of functional occluding pairs $(p<0.020)$ and an increase in dental-treatment needs $(p=0.032)$ remained the most important variables regarding a deterioration of OHRQoL (Table 4). For denture wearers, however, a deterioration of denture condition $(p=0.003)$ remained most relevant regarding a decline in OHRQoL. Detailed results from these analyses are shown in Table 5.

\section{Discussion}

The aim of the study was to evaluate how changes in oral health and chewing efficiency affect the changes in OHRQoL of nursing-home residents over six months. The findings of this study suggest that a decline in oral health and function (ie fewer functional occluding pairs and more treatment needs) is associated with a deterioration of OHRQoL over a six-month period. For denture wearers, the deterioration of denture condition had the most substantial negative effect on OHRQoL.

In this study, OHRQoL did not correlate with age, gender or cognitive impairment $(p>0.05)$, which is in agreement with the literature. ${ }^{11,24}$ Furthermore, this study detected no association between OHRQoL and the level of care needed, although this variable was found to be 
Table 3 Univariate Regression Analysis with GOHAl as the Dependent Variable and Changes in Dental Target Variables of Denture Wearers Over the Study Period as Independent Variables

\begin{tabular}{|c|c|c|c|c|}
\hline Variable & C & $\begin{array}{l}95 \% \mathrm{Cl} \\
\text { LB }\end{array}$ & $\begin{array}{l}95 \% \mathrm{Cl} \\
\text { UB }\end{array}$ & $p$-value \\
\hline \multicolumn{5}{|c|}{ Change in GOHAI $(n=83)$} \\
\hline Age & -0.031 & -0.115 & 0.052 & 0.458 \\
\hline Gender & -0.321 & -2.175 & 1.533 & 0.731 \\
\hline Change in body mass index & -0.011 & -0.397 & 0.376 & 0.957 \\
\hline Change in MMSE score & -0.019 & -0.249 & 0.212 & 0.259 \\
\hline Change in number of teeth & 0.623 & -0.467 & 1.713 & 0.259 \\
\hline $\begin{array}{l}\text { Change in number of } \\
\text { occluding pairs }\end{array}$ & 0.234 & 0.039 & 0.430 & 0.019 \\
\hline $\begin{array}{l}\text { Change in presence of own } \\
\text { teeth }\end{array}$ & 2.775 & -2.353 & 7.903 & 0.285 \\
\hline $\begin{array}{l}\text { Change in total denture } \\
\text { status }\end{array}$ & -0.391 & -2.939 & 2.156 & 0.761 \\
\hline $\begin{array}{l}\text { Change in level of care } \\
\text { needed }\end{array}$ & -0.833 & -4.527 & 2.861 & 0.655 \\
\hline $\begin{array}{l}\text { Change in total treatment } \\
\text { needs }\end{array}$ & -2.611 & -4.976 & -0.247 & 0.031 \\
\hline Change in nutritional status & -0.576 & -2.754 & 1.601 & 0.600 \\
\hline Change in malnutrition & 1.222 & -6.032 & 8.476 & 0.738 \\
\hline $\begin{array}{l}\text { Change in denture } \\
\text { condition }\end{array}$ & -2.946 & -4.827 & -1.065 & 0.003 \\
\hline Change in pressure & -1.124 & -3.364 & 1.116 & 0.321 \\
\hline $\begin{array}{l}\text { Change in chewing function, } \\
\text { objective }(n=79)\end{array}$ & $-1.65 \mid$ & -5.495 & 2.193 & 0.395 \\
\hline $\begin{array}{l}\text { Change in chewing function, } \\
\text { subjective }(n=79)\end{array}$ & -0.076 & -1.855 & 1.702 & 0.932 \\
\hline
\end{tabular}

Note: Significant $p$-values are marked in bold.

Abbreviations: C, regression coefficient; LB, lower boundary; UB, upper boundary; GOHAl, Geriatric Oral Health Assessment Index; MMSE, Mini Mental State Examination; n, number of participants.

Table 4 Multivariate Linear Regression Model After Stepwise Selection of Variables Using the $p$-value with Different Dependent Variables

\begin{tabular}{|c|c|c|c|c|}
\hline Variable & Coefficient & $\begin{array}{r}95 \% \mathrm{Cl} \\
\mathrm{LB}\end{array}$ & $\begin{array}{r}95 \% \mathrm{Cl} \\
\text { UB }\end{array}$ & $p$-value \\
\hline \multicolumn{5}{|c|}{ Change in GOHAI $(n=108)$} \\
\hline Intercept & 0.593 & -0.264 & 1.456 & 0.176 \\
\hline $\begin{array}{l}\text { Change in number } \\
\text { of occluding pairs }\end{array}$ & 0.212 & 0.034 & 0.390 & 0.020 \\
\hline $\begin{array}{l}\text { Change in total } \\
\text { treatment needs }\end{array}$ & -2.169 & -4.150 & -0.189 & 0.032 \\
\hline
\end{tabular}

Note: Significant $p$-values are marked in bold.

Abbreviations: GOHAI, Geriatric Oral Health Assessment Index; LB, lower boundary; UB, upper boundary; $n$, number of participants.

associated with OHRQoL in a different study by Zenthöfer et al. ${ }^{11}$ The use of different measurement tools might account for these differing results. In this context, the
Table 5 Multivariate Linear Regression Model After Stepwise Selection of Variables Using the $p$-value with Different Dependent Variables for Denture Wearers Only

\begin{tabular}{|l|r|r|r|r|}
\hline Variable & Coefficient & $\begin{array}{r}\text { 95\% } \\
\text { CI LB }\end{array}$ & $\begin{array}{r}95 \% \text { CI } \\
\text { UB }\end{array}$ & p-value \\
\hline Change in GOHAI $(\mathbf{n}=83)$ \\
\hline Intercept & 0.4462 & -0.390 & 1.282 & 0.291 \\
Change in denture & -2.946 & 0.945 & -3.117 & $\mathbf{0 . 0 0 3}$ \\
condition & & & & \\
\hline
\end{tabular}

Note: Significant $p$-values are marked in bold.

Abbreviations: GOHAl, Geriatric Oral Health Assessment Index; LB, lower boundary; UB, upper boundary; $n$, number of participants.

German care gradings used in the current study are less precise than the Barthel Index often used in the literature.

In agreement with the results of other recent studies of nursing-home residents, the OHRQoL recorded in this study can be described as inadequate. This might be due to the large number of dental-treatment needs and inadequate dentures among the participants; in cross-sectional studies, these variables have been observed to affect the OHRQoL of nursing-home residents ${ }^{5}$ and communitydwelling adults. ${ }^{25}$ In this study, most participants had dental-treatment needs or inadequate dentures. Furthermore, an increase in dental-treatment needs ( $p=$ $0.031)$ and a deterioration of denture condition $(p=0.003)$ negatively affected the OHRQoL of denture wearers in univariate regression. These results are due to the fact that dental-treatment needs and inadequate dentures are sometimes associated with pain and discomfort and, as a result, can affect OHRQoL. However, some dentaltreatment needs (eg caries, periodontitis, uncomplicated crown fracture), especially in the early stages, do not result in symptoms and therefore do not necessarily affect OHRQoL. Because these treatment needs can affect the fit and comfort of dentures, they might be more relevant for denture wearers. Nevertheless, for denture wearers, a deterioration of denture condition (treatment need, loss of denture) proved even more relevant than dentaltreatment needs ( $p=0.003 ; \mathrm{C}:-2.946)$.

Interestingly, a decrease in the number of teeth and a deterioration of total denture status did not affect OHRQoL, even though both variables have previously been observed to substantially affect OHRQoL. ${ }^{5,13,26}$ This result can be explained by the fact that, during the observation period, only a few teeth were lost, and the total denture status did not change for any participants with an FDP. For denture wearers, however, changes in 
total denture status and denture condition did occur; during the quite short six-month observation period, eight participants lost their teeth or dentures and were thus ENP in at least one jaw. As a result, these participants lost functional occluding pairs, which proved important for OHRQoL (all participants: $p=0.034$; denture wearers: $p=0.019$ ). One could speculate that the loss of functional occluding pairs negatively affected the OHRQoL of the participants because it reduced their chewing efficiency, as has been described in several other studies. ${ }^{5,26}$ However, in this study, changes in chewing efficiency, as evaluated subjectively and objectively by means of the two-colour chewing-gum tests, did not affect OHRQoL. Nonetheless, only small changes in chewing efficiency were observed during the six-month period. Furthermore, it must be kept in mind that the chewing efficiency recorded in this study was lower than that in other studies investigating adults and community-dwelling older people. ${ }^{27,28}$ Possible reasons for this poorer chewing efficiency are a more advanced age, $^{29}$ a high prevalence of cognitive impairment ${ }^{30-32}$ or a compromised total denture status. ${ }^{33,34}$ Because a loss of functional occluding pairs did affect OHRQoL in univariate $(p=0.034)$ and multivariate $(p=0.020)$ analysis, it is possible that having a greater number of functional occluding pairs improves confidence in chewing, even if it might take more time to chew. This could explain why this variable proved even more important than the chewingefficiency test and type of prosthetic restoration. Changes in the MMSE score did not affect the OHRQoL. One reason might be the rather short observation period with only small changes in cognitive status. It has to be kept in mind that studies described no differences between the OHRQoL of participants with and without dementia. ${ }^{11}$ Changes in nutritional status and BMI also did not effect changes in OHRQoL. However, changes in those parameters during the observation period were small. Analysis of the direct impact of the nutritional status and the BMI at baseline indicated a strong correlation. ${ }^{35}$

\section{Strength and Weaknesses of the Study}

It should be recognized that this study was an explorative pilot study. That is why calculation of the sample size was not possible prior to the start of the study. It further should be recognized that not all nursing homes in the federal states and not all participants of the included nursing homes participated in the study, which suggests caution when it comes to interpretation and generalization of the results. However, all potential residents of the participating nursing homes who gave informed consent were included in the study.

It should also be remembered that self-assessments of oral health-related quality of life by older subjects with dementia were performed in this study; this may not be consistently accurate and may lead to underestimation of oral problems. OHRQoL was, however, assessed by use of the GOHAI, which has been reported to enable more successful and sensitive detection of oral problems among compromised older populations than use of the oral health impact profile.

The strength of the study is that the two dentists received comprehensive training and calibration before the start of the study.

\section{Conclusion}

OHRQoL among nursing-home residents is inadequate, and the need for dental and denture-related treatments is high. This study is the first study which found that the main causes of declining OHRQoL among nursing-home residents are a deterioration in oral health (more treatment needs and inadequate denture condition) and a decline in oral function (loss of functional occluding pairs).

Based on the results of this study, it seems strongly advisable to periodically evaluate and adjust dental health and prosthetic condition, respectively, of nursing home residents to maintain acceptable levels of OHRQoL.

\section{Ethical Approval}

All procedures performed in studies involving human participants were in accordance with the ethical standards of the institutional and/or national research committee and with the 1964 Helsinki declaration and its later amendments or comparable ethical standards.

\section{Informed Consent}

Informed consent was obtained from each participant included in the study, or their legal representative.

\section{Acknowledgments}

We are grateful to all the participants in this study for their patience and cooperation. We would also like to thank Hazel Davies, copy editor, for the English-language revision. ALK was supported by the GEROK Program of the University of Heidelberg.

\section{Funding}

This study was not funded. 


\section{Disclosure}

The authors declare that they have no conflicts of interest.

\section{References}

1. Adam H, Preston AJ. The oral health of individuals with dementia in nursing homes. Gerodontology. 2006;23(2):99-105. doi:10.1111/ j.1741-2358.2006.00118.x

2. Montal S, Tramini P, Triay JA, Valcarcel J. Oral hygiene and the need for treatment of the dependent institutionalised elderly. Gerodontology. 2006;23(2):67-72. doi:10.1111/j.1741-2358.2006. 00111.x

3. Zenthöfer A, Dieke R, Dieke A, Wege KC, Rammelsberg P, Hassel AJ. Improving oral hygiene in the long-term care of the elderly-a RCT. Community Dent Oral Epidemiol. 2013;41 (3):261-268. doi:10.1111/cdoe. 12007

4. Naka O, Anastassiadou V, Pissiotis A. Association between functional tooth units and chewing ability in older adults: a systematic review. Gerodontology. 2014;31(3):166-177. doi:10.1111/ger.12016

5. Klotz AL, Hassel AJ, Schröder J, Rammelsberg P, Zenthöfer A. Oral health-related quality of life and prosthetic status of nursing home residents with or without dementia. Clin Interv Aging. 2017;12:659-665. doi:10.2147/CIA.S125128

6. Juthani-Mehta M, De Rekeneire N, Allore H, et al. Modifiable risk factors for pneumonia requiring hospitalization of community-dwelling older adults: the Health, Aging, and Body Composition Study. J Am Geriatr Soc. 2013;61:1111-1118. doi:10.1111/jgs. 12325

7. Scannapieco FA, Rethman MP. The relationship between periodontal diseases and respiratory diseases. Dent Today. 2003;22:79-83.

8. Callahan D. The WHO definition of 'health'. Stud Hastings Cent. 1973;1(3):77-88. doi:10.2307/3527467

9. Hassel AJ, Danner D, Schmitt M, Nitschke I, Rammelsberg P, Wahl HW. Oral health-related quality of life is linked with subjective well-being and depression in early old age. Clin Oral Investig. 2011;15(5):691-697. doi:10.1007/s00784-010-0437-3

10. Klotz AL, Tauber B, Schubert AL, et al. Oral health-related quality of life as a predictor of subjective well-being among older adults-A decade-long longitudinal cohort study. Community Dent Oral Epidemiol. 2018;46(6):631-638. doi:10.1111/cdoe.12416

11. Zenthöfer A, Rammelsberg P, Cabrera T, Schröder J, Hassel AJ. Determinants of oral health-related quality of life of the institutionalized elderly. Psychogeriatrics. 2014;14(4):247-254. doi:10.1111/ psyg. 12077

12. John MT, Koepsell TD, Hujoel P, Miglioretti DL, LeResche L, Micheelis W. Demographic factors, denture status and oral health-related quality of life. Community Dent Oral Epidemiol. 2004;32(2):125-132. doi:10.1111/j.0301-5661.2004.00144.x

13. Abud MC, Figueiredo MD, Dos Santos MB, Consani RL, Marchini L. Correlation of prosthetic status with the GOHAI and TMD indices. Eur J Prosthodont Restor Dent. 2011;19(1):38-42.

14. Inukai M, John MT, Igarashi Y, Baba K. Association between perceived chewing ability and oral health-related quality of life in partially dentate patients. Health Qual Life Outcomes. 2010;8:118. doi:10.1186/1477-7525-8-118

15. Folstein MF, Folstein SE, McHugh PR. "Mini-mental state". A practical method for grading the cognitive state of patients for the clinician. J Psychiatr Res. 1975;12:189-198. doi:10.1016/00223956(75)90026-6

16. Velayudhan L, Ryu SH, Raczek M, et al. Review of brief cognitive tests for patients with suspected dementia. Int Psychogeriatr. 2014;26:1247-1262. doi:10.1017/S1041610214000416

17. Almeida OP. [Mini mental state examination and the diagnosis of dementia in Brazil]. Arq Neuropsiquiatr. 1998;56:605-612. Portuguese. doi:10.1590/S0004-282X1998000400014
18. Tombaugh TN, McIntyre NJ. The mini-mental state examination: a comprehensive review. J Am Geriatr Soc. 1992;40:922-935. doi:10.1111/j.1532-5415.1992.tb01992.x

19. Chalmers J, King P, Spencer AJ, Wright FA, Carter CD. The oral health assessment tool - Validity and reliability. Aust Dent J. 2005;50 (3):191-199. doi:10.1111/j.1834-7819.2005.tb00360.x

20. Schimmel M, Christou P, Herrmann F, Müller F. A two-colour chewing gum test for masticatory efficiency: development of different assessment methods. J Oral Rehabil. 2007;34(9):671-678. doi:10.1111/j.1365-2842.2007.01773.x

21. Halazonetis DJ, Schimmel M, Antonarakis GS, Christou P. Novel software for quantitative evaluation and graphical representation of masticatory efficiency. J Oral Rehabil. 2013;40(5):329-335. doi:10.1111/joor. 12043

22. Hassel AJ, Rolko C, Koke U, Leisen J, Rammelsberg P. A German version of the GOHAI. Community Dent Oral Epidemiol. 2008;36:34-42. doi:10.1111/j.1600-0528.2007.00351.x

23. Atchison KA, Dolan TA. Development of the geriatric oral health assessment index. J Dent Educ. 1990;54:680-687. doi:10.1002/ j.0022-0337.1990.54.11.tb02481.x

24. Ribeiro GR, Costa JL, Ambrosano GM, Garcia RC. Oral health of the elderly with Alzheimer's disease. Oral Surg Oral Med Oral Pathol Oral Radiol. 2012;114(3):338-343. doi:10.1016/j.oooo.2012.03.028

25. Batista MJ, Lawrence HP, de Sousa Mda L. Impact of tooth loss related to number and position on oral health quality of life among adults. Health Qual Life Outcomes. 2014;12:165. doi:10.1186/ s12955-014-0165-5

26. Tramini P, Montal S, Valcarcel J. Tooth loss and associated factors in long-term institutionalised elderly patients. Gerodontology. 2007;24 (4):196-203. doi:10.1111/j.1741-2358.2007.00183.x

27. Schimmel M, Christou P, Miyazaki H, Halazonetis D, Herrmann FR, Müller F. A novel colourimetric technique to assess chewing function using two-coloured specimens: validation and application. J Dent. 2015;43(8):955-964. doi:10.1016/j.jdent.2015.06.003

28. Silva LC, Nogueira TE, Rios LF, Schimmel M, Leles CR. Reliability of a two-colour chewing gum test to assess masticatory performance in complete denture wearers. J Oral Rehabil. 2018;45(4):301-307. doi:10.1111/joor. 12609

29. Toro A, Buschang PH, Throckmorton G, Roldan S. Masticatory performance in children and adolescents with Class I and II malocclusions. Eur J Orthod. 2006;28:112-119. doi:10.1093/ejo/ cji080

30. Kim EK, Lee SK, Choi YH, et al. Relationship between chewing ability and cognitive impairment in the rural elderly. Arch Gerontol Geriatr. 2017;70:209-213. doi:10.1016/j.archger.2017.02.006

31. Tada A, Miura H. Association between mastication and cognitive status: a systematic review. Arch Gerontol Geriatr. 2017;70:44-53. doi:10.1016/j.archger.2016.12.006

32. Weijenberg RA, Scherder EJ, Lobbezoo F. Mastication for the mindthe relationship between mastication and cognition in ageing and dementia. Neurosci Biobehav Rev. 2011;35(3):483-497. doi:10.1016/j.neubiorev.2010.06.002

33. Schimmel M, Katsoulis J, Genton L, Muller F. Masticatory function and nutrition in old age. Swiss Dent J. 2015;125(4):449-454.

34. Wayler AH, Muench ME, Kapur KK, Chauncey HH. Masticatory performance and food acceptability in persons with removable partial dentures, full dentures and intact natural dentition. J Gerontol. 1984;39(3):284-289. doi:10.1093/geronj/39.3.284

35. Zenthöfer A, Ehret J, Zajac M, Kilian S, Rammelsberg P, Klotz AL. The effects of dental status and chewing efficiency on the oral-healthrelated quality of life of nursing-home residents. Clin Interv Aging. 2020;11(15):2155-2164. doi:10.2147/CIA.S273671 


\section{Publish your work in this journal}

Clinical Interventions in Aging is an international, peer-reviewed journal focusing on evidence-based reports on the value or lack thereof of treatments intended to prevent or delay the onset of maladaptive correlates of aging in human beings. This journal is indexed on PubMed Central, MedLine, CAS, Scopus and the Elsevier
Bibliographic databases. The manuscript management system is completely online and includes a very quick and fair peer-review system, which is all easy to use. Visit http://www.dovepress.com/ testimonials.php to read real quotes from published authors. 